\title{
Inhaled treatment of COPD: a Delphi consensus statement
}

\author{
This article was published in the following Dove Press journal: \\ International Journal of COPD \\ 6 March 2017 \\ Number of times this article has been viewed
}

\author{
Vincent Ninane ${ }^{1}$ \\ Jean-Louis Corhay ${ }^{2}$ \\ Paul Germonpré ${ }^{3}$ \\ Wim Janssens ${ }^{4}$ \\ Guy F Joos ${ }^{5}$ \\ Giuseppe Liistro6 \\ Walter Vincken ${ }^{7}$ \\ Sandra Gurdain ${ }^{8}$ \\ Evelyne Vanvlasselaer ${ }^{8}$ \\ An Lehouck ${ }^{8}$
}

'Department of Respiratory Medicine, Saint-Pierre Hospital, Université Libre de Bruxelles, Brussels, ${ }^{2}$ Department of Respiratory Medicine, $\mathrm{CHU}$, Liege, ${ }^{3}$ Department of Respiratory Medicine, AZ Maria Middelares, Ghent, ${ }^{4}$ Department of Respiratory Medicine, Katholieke Universiteit, Leuven, ${ }^{5}$ Department of Respiratory Medicine, Ghent University Hospital, Ghent, ${ }^{6}$ Department of Respiratory Medicine, University Hospitals Saint-Luc, Brussels, ${ }^{7}$ Department of Respiratory Medicine, University Hospital Brussels, Brussels, ${ }^{8}$ Medical Department, Novartis Pharma, Vilvoorde, Belgium

Correspondence: Vincent Ninane Department of Respiratory Medicine, Centre Hospitalier Universitaire Saint-Pierre Service de Pneumologie, Rue Haute, 322, Brussels 1000, Belgium Email vincent_ninane@stpierre-bru.be
Background: Global Initiative for Chronic Obstructive Lung Disease (GOLD) global strategy (2015) provides guidance for the treatment of chronic obstructive pulmonary disease (COPD) with different first-choice options per GOLD category without specification.

Objectives: To evaluate the level of medical experts' consensus on their preferred first-choice treatment within different COPD categories.

Methods: A two-round Delphi Panel consisting of 15 questions was completed by Belgian pulmonologists $(n=31)$ and European $(n=10)$ COPD experts.

Results: Good consensus was reached by both expert groups for long-acting bronchodilators instead of short-acting bronchodilators as first-choice treatment in GOLD A. Single bronchodilation with long-acting muscarinic antagonist (LAMA) was preferred over long-acting $\beta 2$-agonist (LABA) and LABA/LAMA as first-choice treatment in GOLD B and GOLD C. For GOLD D patients based on the forced expiratory volume in 1 second $\left(\mathrm{FEV}_{1}\right)<50 \%$, a very good consensus was reached for LAMA/LABA as first-choice treatment. For GOLD D patients based on frequent or severe exacerbations, there was a good consensus for LABA/LAMA/inhaled corticosteroids (ICS) as first choice in the Belgian group. According to the European experts, both LABA/LAMA and LABA/LAMA/ICS could be the first choice for these patients.

Conclusion: Belgian and European experts recommend long-acting bronchodilators as first-choice treatment. Treatment containing ICS was found only appropriate in patients with $\mathrm{FEV}_{1}<50 \%$ and $\geq 2$ moderate exacerbations or 1 severe exacerbation/year.

Keywords: chronic obstructive pulmonary disease, therapy, long acting muscarinic antagonist, long acting beta agonist, inhaled corticosteroids, guidelines

\section{Introduction}

Chronic obstructive pulmonary disease (COPD) is defined as "a common preventable and treatable disease, characterized by persistent airflow limitation that is usually progressive and associated with an enhanced chronic inflammatory response in the airways and the lung to noxious particles or gases". ${ }^{1}$ Global Initiative for Chronic Obstructive Lung Disease (GOLD) global strategy has long recommended a stepwise approach in COPD management, based on the severity of airflow limitation. Bronchodilators are the mainstay treatment, and inhaled corticosteroids (ICS) can be added in case of frequent exacerbations. ${ }^{2}$ Stratification of patients according to the severity of COPD is important to initiate relevant treatment and is a crucial aspect of a management guideline. In the 2011 update of the GOLD global strategy, severity of symptoms (according to Modified Medical Research Council [mMRC] or COPD Assessment Test scores) and frequency of exacerbations were added next to lung function (forced expiratory volume in 1 second $\left[\mathrm{FEV}_{1}\right]$ ), as important parameters to take into account when recommending treatment. ${ }^{2}$ The main role of the new A-D classification is to 
propose first-choice and alternative medical treatments for COPD patients within these groups.

For GOLD A patients, short-acting bronchodilation as needed is recommended as first-choice treatment. There is limited evidence to support recommendation of long-acting bronchodilation for this group of patients, because trials with long-acting bronchodilators have only been performed in patients with more severe airflow limitation. ${ }^{1}$

For GOLD B patients, treatment with a long-acting bronchodilator is recommended. There is no indication about whether to use a long-acting $\beta 2$-agonist (LABA) or a long-acting muscarinic antagonist (LAMA). Although the GOLD global strategy states that combining bronchodilators of different pharmacological classes may improve efficacy and decrease the risk of side effects, there is no guidance on when to combine two bronchodilators. ${ }^{1}$

Patients belonging to GOLD C and D have been defined as those with a higher risk of disease progression, and first-choice treatments suggested for these patients include LAMA, LABA/ICS, or triple therapy (LABA/LAMA/ICS). ${ }^{1}$ Knowing that GOLD C and D consist of patients with variable lung function and a variable history of exacerbations, which is mirrored by quite distinct prognosis regarding risk of exacerbations and mortality, clear guidance is needed on first-choice treatment depending on patient characteristics. There is, however, only one study directly comparing LAMA with LABA/ICS. ${ }^{3}$ Because of this lack of evidence, current GOLD global strategy gives no guidance on the firstchoice treatment for GOLD C and D patients. ${ }^{4}$ American Thoracic Society (ATS) and European Respiratory Society (ERS) confirm that numerous questions remain concerning the treatment of COPD in the ATS/ERS statement. ${ }^{5}$

Consensus methods, such as the Delphi process, can be useful in synthesizing many factors that guide clinical decision-making. This includes the evidence base and the many factors that often escape empirical study, such as feasibility, burden, and patient and clinician preference. Therefore, a Delphi Panel was conducted (among Belgian pulmonologists and European experts) to identify consensus on first-choice treatment for COPD patients, based on their airflow limitation, symptoms, history of exacerbations, and hospitalizations for an exacerbation.

\section{Methods}

\section{Study objectives}

The objective of this Delphi Panel was to assess the level of consensus among the Belgian and European pulmonologists on the use of inhaled treatments in COPD subclasses. On the basis of GOLD 2015 classifications, different subgroups of
COPD patients were created, according to the severity of airflow limitation, symptoms, history of exacerbations, and hospitalizations for an exacerbation.

\section{The Delphi Panel}

The Delphi Panel is a method for consensus-building using a questionnaire to collect data from a panel of experts. ${ }^{6}$ A major characteristic of the Delphi technique is the feedback process in which group responses obtained during one round are returned to the participants during the next round in the form of statistical summaries. This feedback process allows and encourages the participants to reassess their initial judgments provided in the previous round.

During several discussion sessions, the authors identified existing scientific evidence gaps regarding first-choice inhalation treatment for COPD and formulated 15 questions to poll expert opinion in these areas. A validation of this questionnaire was done by two external reviewers. The questionnaire included closed questions using the 11-point Likert scale, which is a 0 - to 10 -point scale, whereby 5 equals no difference. To identify the rationale of the treatment choice, open questions were added. The complete questionnaire can be found in the Supplementary materials.

The Delphi Panel was organized in two parallel groups: a Belgian group consisting of 35 Belgian COPD pulmonologists and a group of 11 COPD experts from 11 different European countries were contacted. The Belgian participants were identified based on their local expertise in COPD. To represent the European consensus, 11 experts with scientific publications on the topic of COPD, from 11 different European countries, were contacted. To allow for a comparison between local Belgian and European consensus, the data of both groups were analyzed separately.

The questionnaire was sent electronically to the participating physicians in two rounds. After the first round, group responses were analyzed and returned to the participants in the second round. In this second round, in addition to their individual responses and the group responses from the first round, they also received a sample of the experts' rationales for each question. Rationales that were included in the second round were those rationales that were within the consensus range and were given by at least two participants in the first round. In this second round, participants were asked to adapt or confirm their previous answer based on the given information in order to increase the consensus. After two rounds, the overall consensus was assessed.

The questionnaire comprised four patient categories, based on the current GOLD guidelines: COPD patients with $\mathrm{FEV}_{1} \geq 50 \%$, not symptomatic (GOLD A); COPD patients with $\mathrm{FEV}_{1} \geq 50 \%$, 
symptomatic (GOLD B); COPD patients with $\mathrm{FEV}_{1}<50 \%$, but not symptomatic (GOLD C based on $\mathrm{FEV}_{1}<50 \%$ ); symptomatic $\mathrm{COPD}$ patients with either $\mathrm{FEV}_{1}<50 \%$ and/or two exacerbations (requiring treatment with oral corticosteroids and/or antibiotics) and/or one hospitalization for an exacerbation in the previous 12 months (GOLD D). No formal definition was used to categorize the patients as "symptomatic" or "not symptomatic" in this Delphi Panel. The decision was based on the participating physicians' judgment. For each question, a set of predefined answers were provided at both ends of the 11-point Likert scale (Supplementary materials). As the aim of this Delphi Panel was to identify the participants' preferred treatment options from an unbiased perspective, the participants were asked to answer the questions regardless of existing habits and applicable countryspecific reimbursement criteria or treatment recommendations.

As no patients or patient data were implicated at any point, the Saint-Pierre university hospital's ethics committee approved the study and waived the requirement for patient written informed consent.

\section{Data analysis}

Only fully completed questionnaires were taken into account for data analysis. The data were analyzed using descriptive statistics and presented as median (Q2), quartiles, and interquartile range (Q1-Q3). The statistical analyses were performed using SPSS v.24 (IBM Corp., Armonk, NY, USA). The level of consensus (no consensus, some consensus, good consensus, and very good consensus) was based on the central tendency of the responses and the spread of the data (Table 1). ${ }^{7}$

\section{Results}

Thirty-five Belgian COPD pulmonologists and 11 European COPD experts were electronically contacted during the first round. Of these, 32 (94\%) Belgian pulmonologists and $11(100 \%)$ European experts completed the first round of the Delphi Panel. Thirty-one (89\%) Belgian pulmonologists and

Table I Definition of levels of consensus

\begin{tabular}{ll}
\hline $\begin{array}{l}\text { Perfect } \\
\text { consensus }\end{array}$ & All respondents agree on an answer \\
Very good & Median and $50 \%$ of respondents at one integer ${ }^{\mathrm{a}}$ or \\
consensus & $80 \%$ of respondents within one integer of the median \\
Good & $50 \%$ of respondents within one integer of the median or \\
consensus & $80 \%$ of respondents within two integers of the median \\
Some & $50 \%$ of respondents within two integers of the median or \\
consensus & $80 \%$ of respondents within three integers of the median \\
No consensus & All other cases
\end{tabular}

Notes: Adapted from Chest, I19, Baumann M, Strange C, Heffner J., Management of spontaneous pneumothorax an American College of Chest Physicians Delphi consensus statement, 590-602. Copyright (2001), with permission from Elsevier. ${ }^{7}$ a For example, median and $50 \%$ of respondents are both at 7 (integer = point on the Likert scale); ' ${ }^{\circ}$ For example, median is 7 and $80 \%$ of respondents are between 6 and 8 .
10 (91\%) European COPD experts completed both rounds of the Delphi Panel. An overview of the central trends of the responses and the obtained consensus (no, some, good, or very good) are given in Table 2 . The physician's rationales can be found in Table S1.

\section{COPD patients with $\mathrm{FEV}, \geq 50 \%$, not symptomatic (GOLD A)}

A good consensus was reached by both Belgian and European experts to start therapy with long-acting instead of shortacting bronchodilators for COPD patients with $\mathrm{FEV}_{1} \geq 50 \%$ who are not symptomatic (Table 2; question 1.1).

\section{COPD patients with $\mathrm{FEV}, \geq 50 \%$, symptomatic (GOLD B)}

For symptomatic COPD patients with $\mathrm{FEV}_{1} \geq 50 \%$, starting with single bronchodilation was preferred over dual bronchodilation with some consensus among Belgian experts and good consensus among European experts (Table 2; question 2.2). LAMA was preferred over LABA as a firstchoice treatment, with a good consensus among the Belgian experts and some consensus among the European experts. There was a very good consensus in both groups for treatment with a combination of LABA/LAMA when a COPD patient with $\mathrm{FEV}_{1} \geq 50 \%$ remains symptomatic despite treatment with a single bronchodilator (LABA or LAMA; Table 2; questions 2.1-2.3).

When a COPD patient with $\mathrm{FEV}_{1} \geq 50 \%$ had one moderate exacerbation in the previous 12 months despite treatment with a LAMA, there was a very good consensus in the European group for treatment with a LABA/LAMA combination to be the best choice. In the Belgian group, however, there was only some consensus. When a COPD patient with $\mathrm{FEV}_{1} \geq 50 \%$ patient had one moderate exacerbation in the previous 12 months despite treatment with a LABA, a good consensus was reached in both groups for LABA/LAMA to be the best choice (Table 2; questions 2.4 and 2.5).

Both groups recommended with a good consensus that ICS should not be added to the treatment of a symptomatic patient with an $\mathrm{FEV}_{1} \geq 50 \%$ who had one moderate exacerbation during the previous 12 months (Table 2; question 2.6).

\section{COPD patient with $\mathrm{FEV},<50 \%$, but not symptomatic (GOLD C based on $\left.\mathrm{FEV}_{1}<50 \%\right)$}

A good consensus was reached in both groups for LAMA as a first-choice treatment for asymptomatic COPD patients with $\mathrm{FEV}_{1}<50 \%$. Both Belgian and European experts agreed 
Table 2 Central trends and degree of consensus reached after the second round

\begin{tabular}{|c|c|c|c|c|c|}
\hline & Group & QI & Median (Q2) & Q3 & Consensus \\
\hline \multicolumn{6}{|r|}{ e of symptoms? } \\
\hline \multirow[t]{2}{*}{$0=\mathrm{NO} ; \mathrm{I} 0=\mathrm{YES}$} & $\mathrm{BE}$ & 6 & 7 & 8 & Good consensus \\
\hline & EU & 2 & 8 & 8 & Good consensus \\
\hline
\end{tabular}

2.I If a symptomatic COPD patient with $\mathrm{FEV}_{1} \geq 50 \%$ is treated with one long-acting bronchodilator, what should be the first choice?
$0=$ LABA; I $0=$ LAMA
$B E$
5
7
8
Good consensus
Some consensus

2.2 What should be the first choice when treating a symptomatic COPD patient with $\mathrm{FEV}, \geq 50 \%$ ? Single or dual bronchodilation?

$\begin{array}{llllll}0=\text { LABA/LAMA; } 10=\text { LABA/LAMA } & \text { BE } & 2 & 4 & 5 & \text { Some consensus } \\ & \text { EU } & 1 & 2 & 2 & \text { Good consensus }\end{array}$

2.3 When a COPD patient with $\mathrm{FEV}_{1} \geq 50 \%$ remains symptomatic despite treatment with a single bronchodilator, a treatment with a combination of LABA/LAMA is the best choice

$\begin{array}{llllll}0=\text { total disagreement; } 10=\text { complete agreement } & \text { BE } & 8 & 9 & 10 & \text { Very good consensus } \\ & \text { EU } & 10 & 10 & 10 & \text { Very good consensus }\end{array}$

2.4 When a COPD patient with $\mathrm{FEV}, \geq 50 \%$ had one exacerbation (requiring treatment with oral corticosteroids and/or antibiotics, but no hospitalization) in the previous 12 months despite treatment with a LAMA, a combination of LABA/LAMA is the best choice

$\begin{array}{llllll}0=\text { total disagreement; } 10=\text { complete agreement } & \text { BE } & 3 & 5 & 7 & \text { Some consensus } \\ & \text { EU } & 8 & 9 & 10 \quad \text { Very good consensus }\end{array}$

2.5 When a COPD patient with $\mathrm{FEV}_{1} \geq 50 \%$ had one exacerbation (requiring treatment with oral corticosteroids and/or antibiotics, but no hospitalization) in the previous 12 months despite treatment with a LABA, a combination of LABA/LAMA is the best choice

$\begin{array}{llllll}0=\text { total disagreement; } 10=\text { complete agreement } & \text { BE } & 5 & 7 & 8 & \text { Good consensus } \\ & \text { EU } & 7 & 8 & 10 & \text { Good consensus }\end{array}$

2.6 When a COPD patient with $\mathrm{FEV}_{1} \geq 50 \%$ had one exacerbation (requiring treatment with oral corticosteroids and/or antibiotics, but no hospitalization) in the previous 12 months, an ICS should be added

$\begin{array}{llllll}0=\text { total disagreement; } 10=\text { complete agreement } & \text { BE } & 2 & 3 & 4 & \text { Good consensus } \\ & \text { EU } & 0 & 2 & 3 & \text { Good consensus }\end{array}$

3.I COPD patient with $\mathrm{FEV}_{1}<50 \%$, but not symptomatic. What should be the first choice when treating this patient? $(0=$ total disagreement; $10=$ complete agreement)
a) SABA/SAMA
$\begin{array}{lll}B E & 1 & 2 \\ \text { EU } & 0 & 0\end{array}$
b) LABA
$\mathrm{BE}$
c) LAMA
EU
BE
EU
d) LABA/ICS
e) LABA/LAMA
$B E$
EU
$B E$
EU
f) LABA/LAMA/ICS
BE
EU

$\begin{array}{ll}2 & 5 \\ 0 & 0 \\ 6 & 7 \\ 1.5 & 4 \\ 7 & 8 \\ 8 & 1 \\ 1 & 3 \\ 0.5 & 2 \\ 6 & 8 \\ 5 & 6 \\ 1 & 2 \\ 0 & 3\end{array}$
Good consensus
Very good consensus
Good consensus
Some consensus
Good consensus
Good consensus
Good consensus
Good consensus
Good consensus
Very good consensus
Very good consensus
Very good consensus

4.I What should be the first choice when treating a symptomatic COPD patient, with $\mathrm{FEV},<50 \%$, but no exacerbations in the previous 12 months? $(0=$ total disagreement; $10=$ complete agreement $)$
a) LAMA
b) LABA/ICS

BE
EU
BE
EU
c) LABA/LAMA
BE
EU
d) LABA/LAMA/ICS
$\mathrm{BE}$
EU

$\begin{array}{ll}5 & 6 \\ 0 & 5 \\ 1 & 2 \\ 0 & 0 \\ 7 & 8 \\ 8 & 9 \\ 1 & 2 \\ 0 & 2\end{array}$

$\begin{array}{ll}6 & 8 \\ 5 & 10 \\ 2 & 4 \\ 0.5 & 3 \\ 8 & 9 \\ 9 & 10 \\ 2 & 3 \\ 2 & 5\end{array}$
Some consensus
No consensus
Good consensus
Good consensus
Very good consensus
Very good consensus
Good consensus
Some consensus

4.2 If the same patient, with $\mathrm{FEV}_{1}<50 \%$, but no exacerbations in the previous 12 months remains symptomatic after initial treatment with a LAMA, what should be the most appropriate treatment? $(0=$ total disagreement; $10=$ complete agreement $)$
a) LABA
$B E$
I 2
0.5
Good consensus
b) LABA/ICS
BE
1
c) LABA/LAMA
EU
I
d) LABA/LAMA/ICS
BE
EU
BE
0.5
Good consensus
Good consensus
Very good consensus
Very good consensus
Very good consensus
Good consensus
Some consensus

(Continued) 
Table 2 (Continued)

\begin{tabular}{|c|c|c|c|c|c|}
\hline & Group & QI & Median (Q2) & Q3 & Consensus \\
\hline \multicolumn{6}{|c|}{$\begin{array}{l}4.3 \text { If the same patient, with } \mathrm{FEV}_{1}<50 \% \text {, but no exacerbations in the previous } 12 \text { months remains symptomatic after initial treatment with a } \mathrm{LABA} \text {, } \\
\text { what should be the most appropriate treatment? ( } 0=\text { total disagreement; } 10=\text { complete agreement) }\end{array}$} \\
\hline \multirow[t]{2}{*}{ a) LAMA } & $\mathrm{BE}$ & 3 & 4 & 5 & Good consensus \\
\hline & EU & 0 & 0.5 & 4 & Good consensus \\
\hline \multirow[t]{2}{*}{ b) LABA/ICS } & $\mathrm{BE}$ & I & 1 & 3 & Good consensus \\
\hline & EU & 0 & 0.5 & 2 & Good consensus \\
\hline \multirow[t]{2}{*}{ c) LABA/LAMA } & $\mathrm{BE}$ & 8 & 9 & 10 & Very good consensus \\
\hline & EU & 10 & 10 & 10 & Very good consensus \\
\hline \multirow[t]{2}{*}{ d) LABA/LAMA/ICS } & $\mathrm{BE}$ & 1 & 2 & 3 & Good consensus \\
\hline & EU & 0 & 1.5 & 4 & Some consensus \\
\hline
\end{tabular}

4.4 If a symptomatic COPD patient has an $\mathrm{FEV}_{1}<50 \%$ but only one exacerbation (requiring treatment with oral corticosteroids and/or antibiotics, but no hospitalization) in the previous 12 months, what should be the first-choice treatment? ( $0=$ total disagreement; $10=$ complete agreement)

\begin{tabular}{|c|c|c|c|c|c|}
\hline \multirow[t]{2}{*}{ a) LAMA } & $\mathrm{BE}$ & 4 & 5 & 7 & Good consensus \\
\hline & EU & 2 & 7.5 & 10 & No consensus \\
\hline \multirow[t]{2}{*}{ b) LABA/ICS } & $\mathrm{BE}$ & I & 2 & 4 & Good consensus \\
\hline & EU & 0 & 0.5 & 2 & Good consensus \\
\hline \multirow[t]{2}{*}{ c) LABA/LAMA } & BE & 8 & 9 & 9 & Very good consensus \\
\hline & EU & 8 & 9 & 10 & Very good consensus \\
\hline \multirow[t]{2}{*}{ d) LABA/LAMA/ICS } & $\mathrm{BE}$ & 2 & 3 & 5 & Good consensus \\
\hline & EU & 0 & 0.5 & 4 & Good consensus \\
\hline
\end{tabular}

4.5 If a COPD patient has an $\mathrm{FEV}_{1}<50 \%$ and two exacerbations (requiring treatment with oral corticosteroids and/or antibiotics) or one hospitalization for an exacerbation in the previous 12 months, what should be the first-choice treatment? $(0=$ total disagreement; $10=$ complete agreement)

$\begin{array}{llllll}\text { a) LAMA } & \mathrm{BE} & 2 & 3 & 5 & \text { Good consensus } \\ \text { b) LABA/ICS } & \mathrm{EU} & 0 & 0 & 3 & \text { Very good consensus } \\ & \mathrm{BE} & 4 & 6 & 8 & \text { Some consensus } \\ \text { c) LABA/LAMA } & \mathrm{EU} & 5 & 6 & 8 & \text { Good consensus } \\ & \mathrm{BE} & 4 & 5 & 7 & \text { Good consensus } \\ \text { d) LABA/LAMA/ICS } & \mathrm{EU} & 6 & 8 & 8 & \text { Good consensus } \\ & \mathrm{BE} & 8 & 9 & 9 & \text { Good consensus } \\ & \mathrm{EU} & 6 & 8 & 8 & \text { Good consensus }\end{array}$

4.6 An ICS should always be added to the treatment if a COPD patient had two or more exacerbations (requiring treatment with oral corticosteroids and/or antibiotics, but no hospitalization) in the previous 12 months

$\begin{array}{llllll}(0=\text { total disagreement; } 10=\text { complete agreement }) & \mathrm{BE} & 6 & 7 & 8 & \text { Good consensus } \\ & \mathrm{EU} & 5 & 6.5 & 8 & \text { Some consensus }\end{array}$

4.7 An ICS should always be added to the treatment if a COPD patient had an exacerbation requiring a hospitalization in the previous 12 months

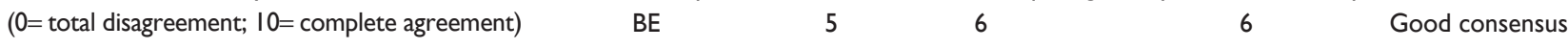

EU $\quad 5 \quad 6 \quad 8 \quad$ Good consensus

Abbreviations: $B E$, Belgium pneumologists $(n=31)$; COPD, chronic obstructive pulmonary disease; EU, European experts $(n=10)$; $F E V_{1}$, forced expiratory volume in I second; ICS, inhaled corticosteroids; LABA, long-acting 32 -agonist; LAMA, long-acting muscarinic antagonist; QI, first quartile; Q2, second quartile or median; Q3, third quartile.

that treatments containing ICS (LABA/ICS or LABA/ LAMA/ICS) are not an appropriate first-choice treatment in this category of patients (Table 2; question 3.1).

\section{Symptomatic COPD patients with either $\mathrm{FEV},<50 \%$ and/or two exacerbations and/or one hospitalization for an exacerbation in the previous 12 months (GOLD D)}

There was a very good consensus in both groups for LABA/ LAMA as a first-choice treatment for symptomatic COPD patients, with $\mathrm{FEV}_{1}<50 \%$, but no exacerbations in the previous 12 months. Most experts in both groups agreed that treatments containing ICS, either LABA/ICS or LABA/ LAMA/ICS, are not appropriate for patients with $\mathrm{FEV}_{1}<50 \%$, but no exacerbations in the previous 12 months (some and good consensus). If a COPD patient, with $\mathrm{FEV}_{1}<50 \%$ but no exacerbations, remained symptomatic after treatment with a single bronchodilator, there was a very good consensus for LABA/LAMA being the best choice treatment. If the same patient had one moderate exacerbation (requiring treatment with oral corticosteroids and/or antibiotics, but no hospitalization) in the previous 12 months, there was a very good consensus for LABA/LAMA being the best choice treatment. Both groups agreed, with a good consensus, that treatments 
containing ICS, either LABA/ICS or LABA/LAMA/ICS, are not appropriate for this category of patients (Table 2; questions 4.1-4.4).

A LABA/LAMA/ICS combination was recommended as a first-choice treatment by the Belgian experts, with a good consensus, for patients with $\mathrm{FEV}_{1}<50 \%$ and two moderate or one severe exacerbation in the previous 12 months. In the European group, however, both LABA/LAMA and LABA/ LAMA/ICS were selected as first-choice treatments (Table 2; question 4.5).

In case of two or more moderate/severe exacerbations, there was a good consensus among Belgian and some consensus among the European COPD experts to add an ICS to the treatment. In case of a hospitalization for an exacerbation, a good consensus but only a median score of 6 was reached by both Belgian and European groups to add an ICS to the treatment (Table 2; questions 4.6 and 4.7).

\section{Discussion}

A Delphi Panel was used to obtain consensus on the use of inhaled treatments in different COPD patient categories based on the level of symptoms, airflow obstruction, and exacerbation history. This study, conducted among 31 Belgian and 10 European COPD experts, showed a good consensus to start therapy with long-acting bronchodilators, regardless of symptoms. LAMAs were preferred over LABAs as a first-choice single bronchodilator. According to both Belgian and European experts, dual bronchodilation should be preferred to single bronchodilation for treatment initiation in case of low $\mathrm{FEV}_{1}$ associated with symptoms with or without exacerbation history. ICS-containing treatments were only recommended for treatment initiation of patients with low $\mathrm{FEV}_{1}$ and symptoms, provided there was at least two moderate or one severe exacerbation. Figure 1 gives an overview of European and Belgian experts' consensus on first-choice treatment for COPD.

\section{Long-acting bronchodilation therapy as part of the maintenance treatment of all COPD patients}

At least one long-acting bronchodilator was recommended by both Belgian and European experts for all the clinical conditions, and a good consensus was even reached for a long-acting bronchodilator as first-choice treatment in asymptomatic patients with $\mathrm{FEV}_{1} \geq 50 \%$. This is in contrast with the GOLD global strategy, which advises short-acting bronchodilators, as needed, as first-choice treatment for GOLD A patients, even if some COPD experts already recommended
LABA or LAMA in benign diseases associated with low levels of symptoms and risks. ${ }^{1,8}$ This would, however, require further investigation because most studies with long-acting bronchodilators were performed with patients with more severe airflow limitation. ${ }^{9,10}$ Within the scope of the Delphi Panel, this choice was justified by the underestimation of symptoms by patients who may have already experienced reduced physical activity, as previously suggested by Pitta et al. ${ }^{11}$ In this respect, it is important to stress the lack of a gold standard to assess dyspnea. ${ }^{12}$ In clinical practice, mMRC is often used to assess dyspnea and its use is recommended in guidelines. ${ }^{1}$ There are, however, uncertainties about the cutoff (grade 2) used to define a high level of symptoms because recent studies suggest that $\mathrm{mMRC}$ grade 1 may already be associated with a significant impact. ${ }^{13}$ Recent data even suggest that some $50 \%$ of current or former smokers with preserved pulmonary function have respiratory symptoms that are associated with activity limitation and exacerbation risk and indeed, many of them already use bronchodilators. ${ }^{14}$ Finally, subanalysis data of the UPLIFT study have demonstrated a significant effect of tiotropium on lung function decline and disease progression in GOLD 2 patients and patients without maintenance treatment. ${ }^{15,16}$

\section{LAMAs as preferred long-acting bronchodilators}

For patients with $\mathrm{FEV}_{1} \geq 50 \%$, results of this Delphi Panel demonstrated a preference for LAMA over LABA as a first-choice long-acting bronchodilator for both Belgian and European experts. This is supported by the better exacerbation-preventing effect of LAMA. ${ }^{17,18}$ For patients with $\mathrm{FEV}_{1}<50 \%$, without symptoms, there was a good consensus in both the Belgian and European groups for a LAMA as a first-choice treatment.

\section{Treatment initiation with one single agent or immediate dual bronchodilation}

With the introduction of fixed-dose dual-bronchodilation therapies, the question remains if treatment should be started with one single agent and then further stepped up if symptoms are not controlled or dual-bronchodilation therapy should be initiated immediately. According to the results of the Delphi Panel, Belgian and European experts support both strategies but in a different clinical context. They would start with one single agent, either LABA or LAMA, for symptomatic patients with $\mathrm{FEV}_{1} \geq 50 \%$ (GOLD B) and with dual bronchodilation for symptomatic patients with more severe airway obstruction (GOLD D). The European 
A
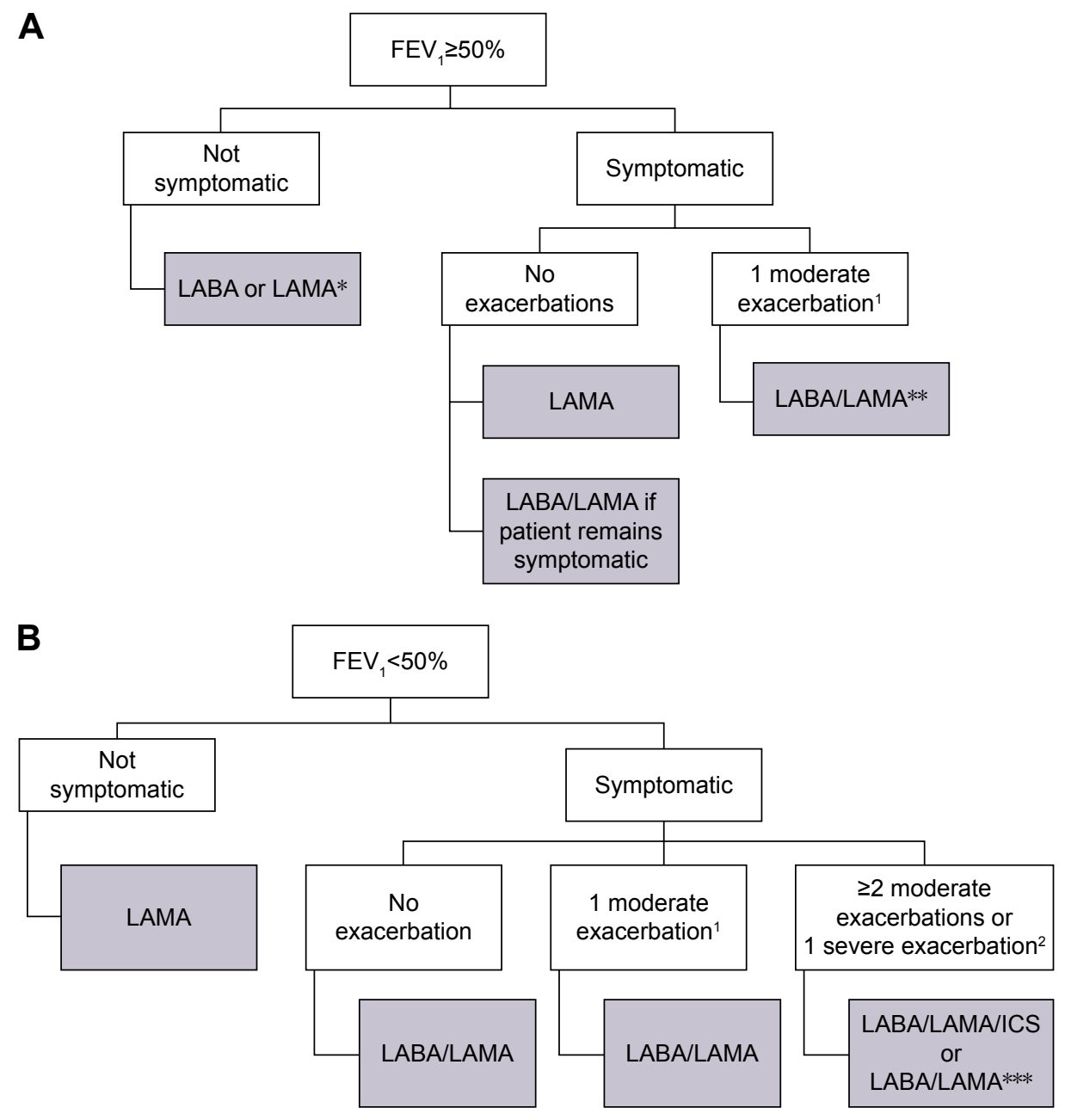

Figure I Overview of expert's consensus on first-choice treatment for COPD patients.

Notes: This figure gives a schematic overview of experts consensus on first-choice treatment for COPD patients with $\mathrm{FEV}, \geq 50 \%(\mathbf{A})$ and $\mathrm{FEV},<50 \%(\mathbf{B}) . * \mathrm{The}_{1}$ preference for a LAMA or a LABA was not investigated for patients with $\mathrm{FEV}<50 \%$ who are not symptomatic. **According to the Belgian consensus, switch to LABA/LAMA is only needed if patients have one exacerbation (requiring treatment with oral corticosteroids and/or antibiotics), despite treatment with a LABA, and not despite treatment with LAMA. ***B Belgian consensus was only reached for LABA/LAMA/ICS; European consensus was reached for both LABA/LAMA/ICS and LABA/LAMA. 'Moderate exacerbation = exacerbations requiring treatment with oral corticosteroids and/or antibiotics in the previous 12 months. ${ }^{2} \geq 2$ moderate exacerbations or $I$ severe exacerbation $=\geq 2$ exacerbations (requiring treatment with oral corticosteroids and/or antibiotics) or I hospitalization for an exacerbation in the previous I 2 months.

Abbreviations: COPD, chronic obstructive pulmonary disease; FEV , forced expiratory volume in I second; ICS, inhaled corticosteroids; LABA, long-acting $\beta 2$-agonist; LAMA, long-acting muscarinic antagonist.

experts justify starting with a single agent by the possibility to step up. For the Belgian experts, the choice to start with one single bronchodilator or dual bronchodilation would depend on the severity of airflow limitation. When a patient remains symptomatic, despite treatment with a single bronchodilator, or when the level of airflow obstruction is higher $\left(\mathrm{FEV}_{1} \leq 50 \%\right)$, and in case exacerbations are not frequent or severe, there was a very good consensus for LABA/LAMA combinations as first-choice treatments among both groups of experts. Better symptom control, maximum bronchodilation, and no need for ICS because of infrequent occurrence or moderate severity of exacerbations were some of the rationales given to support this choice. However, LAMA/LABA as a first-choice treatment for patients with $\mathrm{FEV}_{1}<50 \%$ is not in line with the current GOLD global strategy, which advises LAMA, LABA/ICS, or LABA/LAMA/ICS treatment for GOLD C-D patients, and LABA/LAMA combinations as alternative treatment options. ${ }^{1}$

\section{Treatment containing ICS only appropriate for patients with $\mathrm{FEV}_{1}<50 \%$ and frequent or severe exacerbations}

Treatments containing ICS, either LABA/ICS or LABA/ LAMA/ICS, were only found to be an appropriate choice for patients with an $\mathrm{FEV}_{1}<50 \%$ and two moderate or one severe exacerbation in the previous 12 months. Studies comparing dual bronchodilation with a fixed-dose LABA/ICS combination have shown superiority of dual bronchodilation on 
lung function and dyspnea compared to LABA/ICS. ${ }^{19,20}$ The latter is further supported by the recently published FLAME study highlighting the superiority of LABA/LAMA over LABA/ICS on both lung function and exacerbations, for patients with a history of at least one exacerbation. ${ }^{21}$ The choice of adding an ICS on top of a dual-bronchodilation therapy depends, according to both Belgian and European experts, on the individual patient and potential risk of adverse events. Due to substantial adverse effects from the use of ICS in patients with COPD, the risk/benefit ratio of ICS should always be taken into account. The FLAME study demonstrated significantly more pneumonia in patients with a history of at least one exacerbation treated with LABA/ICS compared to LABA/LAMA. ${ }^{21}$ There is an urgent need for markers of benefit and risk that can be tested in randomized trials for use in routine specialist practice. ${ }^{22}$ Nevertheless, in contrast with the recommendation of the Delphi Panel, ICS have been used widely, with recent trials observing that $>70 \%$ of COPD patients were treated with ICS at the time of enrollment. Evidence is mounting that such extensive use of ICS is discrepant with COPD treatment guidelines and may be inappropriate. ${ }^{23,24}$ Results of the WISDOM study, a step-down study from LABA/LAMA/ICS to dual bronchodilation, and the FLAME study that demonstrated a significant decrease of exacerbations with LABA/LAMA compared to LABA/ICS for patients with a history of at least one exacerbation question the absolute need of ICS for the prevention of exacerbations. ${ }^{25,21}$

\section{Strengths and limitations}

The use of formal consensus techniques in medicine is becoming increasingly frequent. Consensus techniques such as the Delphi technique can be helpful in making decisions in situations where no gold standard exists or evidence is lacking. However, results of panel consensus judgment are only considered category D evidence according to GOLD 2015 recommendations. ${ }^{1}$

The limitations of this study are 1) that the use of closed questions and multiple-choice questions may have limited responses or induced bias; ${ }^{26}$ 2) although participants were instructed to complete the Delphi Panel regardless of current recommendations and reimbursement criteria, differences between the two groups may reflect geographically driven practices and biases. The fact that LAMA and LABA/ LAMA are subject to more restricted reimbursement criteria in Belgium compared with LABA and LABA/ICS could possibly explain the higher consensus scores for LABA for the Belgian compared to the European group.

\section{Conclusion}

This Delphi Panel answers some of the questions that remained unanswered in the GOLD global strategy. Few differences were observed between the European and Belgian experts in their respective consensus on the firstchoice treatment for COPD. Long-acting bronchodilators are recommended as a first-choice treatment for COPD patients without frequent and/or severe exacerbations, regardless of symptoms, with differences between Belgium pneumologists and European experts in the choice between LABA, LAMA, and LABA/LAMA. A very good consensus was reached in both groups to step up to LABA/LAMA when a single agent is not sufficient and for LABA/LAMA as a preferred firstchoice treatment over LABA/ICS for more severe patients with infrequent moderate exacerbations ( $\leq 1$ exacerbation). Treatment containing ICS was only found appropriate for patients with $\mathrm{FEV}_{1}<50 \%$ and $\geq 2$ moderate exacerbations or 1 severe exacerbation according to both Belgian and European experts.

\section{Acknowledgments}

The authors would like to thank the European experts and Belgian pulmonologists who contributed to this Delphi Panel: Francesco Blasi, Joao Cardoso, Alexander Chuchalin, David Halpin, Hannu Kankaanranta, Marc Miravitlles, Nicolas Roche, Thomas Sandström, Paweł Śliwiński, Claus Vogelmeier, Jaromír Zatloukal, Sandra Baldassarre, Lieven Bedert, Peter Bomans, Greta Bral, Didier Cataldo, Christophe Compere, Alain Delobbe, Ingel Demedts, Bart De Saedeleer, Paul De Vuyst, Peter Driesen, Rik Gubbelmans, Christel Haenebalcke, Michiel Haerens, Vincent Heinen, Hans Jonnaert, Paul Jordens, Jan Lamont, Alexandre Legrand, Eric Marchand, Jean-Benoit Martinot, Catherine Mercenier, Evert Munghen, Alain Palem, Rudi Peché, Manu Potvin, Pol Ravez, Hans Struyven, Geert Tits, Yvan Valcke, Paul Van den Brande, Peter Van Haecke, Dirk Van Renterghem, and Andre Verstraeten.

The authors acknowledge assistance from XPE Pharma and Science (Belgium) for the statistical analyses and for the preparation of the web-based questionnaires. Novartis was the funding source and was involved in all stages of the survey conduct and analysis. Discussions for this publication took place at advisory board meetings supported by Novartis.

\section{Author contributions}

All authors contributed toward data analysis, drafting and revising the paper and agree to be accountable for all aspects of the work. 


\section{Disclosure}

VN has been on advisory boards for GlaxoSmithKline (GSK), AstraZeneca (AZ), Novartis (N), and Boehringer Ingelheim (BI). $\mathrm{PG}$ received fees for attending advisory board from $\mathrm{N}$, AZ, GSK, and BI. He also received educational grant from Chiesi (C). WJ has been on advisory boards and has accepted lecture fees from GSK, AZ, N, C and BI. GFJ has been on advisory boards or has accepted fees for lecture from GSK, AZ, N, C, BI, Mundipharma, Sandoz and Teva. GL has been on advisory boards for N, BI, and C. WV has been on advisory board for N, GSK, AZ, BI, and C including travel expenses from BI. SG, and EV are both employees of N. JLC and AL declared no conflicts of interest. The authors report no other conflicts of interest in this work.

\section{References}

1. Global Initiative for Chronic Obstructive Lung Disease (GOLD 2016). Global Strategy for the Diagnosis, Management and Prevention of Chronic Obstructive Pulmonary Disease [Updated: December, 2015]. Available from: www.goldcopd.org. Accessed May 23, 2016.

2. Johannessen A, Nilsen R, Storebø M, et al. Comparison of 2011 and 2007 global initiative for chronic obstructive lung disease guidelines for predicting mortality and hospitalization. Am J Respir Crit Care Med. 2013;188(1):51-59.

3. Wedzicha J, Calverley P, Seemungal T, Hagan G, Ansari Z, Stockley RA; INSPIRE Investigators. The prevention of chronic obstructive pulmonary disease exacerbations by salmeterol/fluticasone propionate or tiotropium bromide. Am J Respir Crit Care Med. 2008;177(1):19-26.

4. Lange P, Marott J, Vestbo J, et al. Prediction of the clinical course of chronic obstructive pulmonary disease, using the new GOLD classification: a study of the general population. Am J Respir Crit Care Med. 2012;186(10):975-981.

5. Celli B, Decramer M, Wedzicha J, et al. An Official American Thoracic Society/European Respiratory Society Statement: Research questions in chronic obstructive pulmonary disease. Eur Respir J. 2015; 45(4):879-905

6. Fink A, Kosecoff J, Chassin M, Brook RH. Consensus methods: characteristics and guidelines for use. Am J Public Health. 1984;74(9): 979-983.

7. Baumann M, Strange C, Heffner J. Management of spontaneous pneumothorax: an American College of Chest Physicians Delphi consensus statement. Chest. 2001;119(2):590-602.

8. Pavord I, Agusti A. Blood eosinophil count: a biomarker of an important treatable trait in patients with airway disease. Eur Respir J. 2016; 47(5):1299-1303.

9. Barr RG, Bourbeau J, Camargo CA, Ram FS. Inhaled tiotropium for stable chronic obstructive pulmonary disease. Cochrane Database Syst Rev. 2005;2:CD002876.
10. Appleton $\mathrm{S}$, Jones $\mathrm{T}$, Poole $\mathrm{P}$, et al. Ipratropium bromide versus longacting beta-2 agonists for stable chronic obstructive pulmonary disease. Cochrane Database Syst Rev. 2006;3:CD006101.

11. Pitta F, Troosters T, Spruit MA, Probst VS, Decramer M, Gosselink R. Characteristics of physical activities in daily life in chronic obstructive pulmonary disease. Am J Respir Crit Care Med. 2005;171(9): 972-977.

12. Perez T, Burgel P, Paillasseur J, et al. Modified Medical Research Council scale vs Baseline Dyspnea Index to evaluate dyspnea in chronic obstructive pulmonary disease. Int J Chron Obstruct Pulmon Dis. 2015;10:1663-1672.

13. Jones P, Adamek L, Nadeau G, Banik N. Comparisons of health status scores with MRC grades in COPD: implications for the GOLD 2011 classification. Eur Respir J. 2013;42(3):647-654.

14. Woodruff P, Barr R, Bleecker E, et al. Clinical significance of symptoms in smokers with preserved pulmonary function. $N$ Engl J Med. 2016;374(19):1811-1821.

15. Decramer M, Celli B, Kesten S, et al. Effect of tiotropium on outcomes in patients with moderate chronic obstructive pulmonary disease (UPLIFT): a prespecified subgroup analysis of a randomised controlled trial. Lancet. 2009;374(9696):1171-1178.

16. Troosters T, Celli B, Lystig T, et al. Tiotropium as a first maintenance drug in COPD: secondary analysis of the UPLIFT trial. Eur Respir J. 2010; 36(1):65-73.

17. Vogelmeier C, Hederer B, Glaab T, et al. Tiotropium versus salmeterol for the prevention of exacerbations of COPD. $N$ Engl J Med. 2011; 364(12):1093-1103.

18. Decramer M, Chapman K, Dahl R, et al. Once-daily indacaterol versus tiotropium for patients with severe chronic obstructive pulmonary disease (INVIGORATE): a randomised, blinded, parallel-group study. Lancet Respir Med. 2013;1(7):524-533.

19. Zhong N, Wang C, Zhou X, et al. LANTERN: a randomized study of QVA149 versus salmeterol/fluticasone combination in patients with COPD. Int J Chron Obstruct Pulmon Dis. 2015;10:1015-1026.

20. Vogelmeier C, Bateman E, Pallante J, et al. Efficacy and safety of oncedaily QVA149 compared with twice-daily salmeterol-fluticasone in patients with chronic obstructive pulmonary disease (ILLUMINATE): a randomised, double-blind, parallel group study. Lancet Respir Med. 2013;1(1):51-60.

21. Wedzicha J, Banerji D, Chapman KR, et al. Indacaterol-Glycopyrronium versus Salmeterol-Fluticasone for COPD. N Engl J Med. 2016; 374(23):2222-2234.

22. Ernst P, Saad N, Suissa S. Inhaled corticosteroids in COPD: the clinical evidence. Eur Respir J. 2015;45(2):525-537.

23. Corrado A, Rossi A. How far is real life from COPD therapy guidelines? An Italian observational study. Respir Med. 2012;106(7):989-997.

24. Roche N, Pribil C, Van Ganse E, et al. Real-life use of fluticasone propionate/salmeterol in patients with chronic obstructive pulmonary disease: a French observational study. BMC Pulm Med. 2014;14:56.

25. Magnussen H, Disse B, Rodriguez-Roisin R, et al. Withdrawal of inhaled glucocorticoids and exacerbations of COPD. $N$ Engl J Med. 2014;371:1285-1294.

26. Hasson F, Keeney S, McKenna H. Research guidelines for the Delphi survey technique. J Adv Nurs. 2000;32(4):1008-1015.
International Journal of COPD

\section{Publish your work in this journal}

The International Journal of COPD is an international, peer-reviewed journal of therapeutics and pharmacology focusing on concise rapid reporting of clinical studies and reviews in COPD. Special focus is given to the pathophysiological processes underlying the disease, intervention programs, patient focused education, and self management protocols.

\section{Dovepress}

This journal is indexed on PubMed Central, MedLine and CAS. The manuscript management system is completely online and includes a very quick and fair peer-review system, which is all easy to use. Visit http://www.dovepress.com/testimonials.php to read real quotes from published authors. 